\title{
ANALISIS EKONOMI PROGRAM KAWASAN INDUSTRI AGRO TERPADU (KIAT) PROVINSI GORONTALO
}

\author{
Theodora M. Katiandagho \\ M. Sendow \\ J. Baroleh \\ Sriyani Wahyuni Tangahu
}

\begin{abstract}
This research has been conducted in the Integrated Agro Industrial Area (TIP) Province of Gorontalo in November 2010 using the data and using linear programming models. The research aims to find the product combination of corn chips, nuts disco, peanuts eggs should be produced to achieve maximum profit, find out how much the maximum advantage can be achieved by TIPS, and TIPS determine the pattern of production, it is optimal or not. The results showed that the combination product should be produced (packaging / wrappers) sequentially from X1 to X13 are 2545, 314, 76.130, 344, $509,331,172,7,311,180,854,7$. The combination product is a combination of products that can provide maximum benefit. The maximum profit that can be achieved by following the TIP with the combination product that is equal to Rp8.770.206. This advantage is greater than the actual clappers TIPS. TIPS production pattern is not optimal, because for some products there is still a considerable difference between the optimal production and actual production in which the optimal production gives better results (large), and also there is no actual product produced equal to optimal production.
\end{abstract}

Keywords: Agro Industrial Area, Linear Programming Models, Product Combination

\section{PENDAHULUAN}

\section{Latar Belakang}

Sektor pertanian merupakan sektor yang mempunyai peranan strategis dalam struktur pembangunan perekonomian nasional. Potensi Sumber Daya Alam yang besar dan beragam, pangsa terhadap pendapatan nasional yang cukup besar, besarnya pangsa terhadap ekspor nasional, besarnya penduduk Indonesia yang menggantungkan hidupnya pada sektor ini, perannya dalam penyediaan pangan masyarakat dan menjadi basis pertumbuhan di pedesaan semakin memperkuat peran strategis dari sektor pertanian (Firmansah, 2010). Sektor ini mampu menyediakan lapangan kerja, mendukung sektor industri baik industri hulu maupun industri hilir. Kemajuan sektor pertanian akan menyebabkan pembangunan di sektor yang didukung oleh sektor pertanian, semakian maju pula (Rachmawati, 2010).
Salah satu wilayah negara Indonesia yang memiliki potensi besar di bidang pertanian yaitu Provinsi Gorontalo. Provinsi Gorontalo merupakan provinsi baru pemekaran dari Provinsi Sulawesi Utara yang dibentuk berdasarkan Undang-undang Nomor 38 tahun 2000, yang kemudian diresmikan pada 16 Februari 2001. Sebagai provinsi baru yang juga melaksanakan otonomi daerah, provinsi ini dituntut untuk mampu merencanakan, melaksanakan, dan mengelola pembangunan wilayahnya. Pembangunan di Provinsi Gorontalo dituang dalam beberapa program unggulan pemerintah yaitu pengembangan sumberdaya manusia, pengembangan sektor pertanian, dan pengembangan sektor perikanan dan kelautan.

Upaya pemerintah untuk mengembangkan sektor pertanian dilaksanakan melalui program unggulan agropolitan berbasis jagung. Jagung dipilih sebagai komoditas andalan didasarkan karena jagung merupakan tanaman yang telah 
diusahakan sejak dulu, dan merupakan salah satu makanan pokok masyarakat Gorontalo selain beras. Selain itu, hal ini juga didukung oleh keadaan wilayah yang sesuai untuk pertumbuhan jagung (Dinas Pertanian dan Ketahanan Pangan Provinsi Gorontalo, 2006). Program agropolitan yang mulai dilaksanakan sejak tahun 2002 silam, berpengaruh terhadap produktivitas jagung.

Tabel 1. Luas Panen, Produksi, dan Produktivitas Jagung di Provinsi Gorontalo, 2002-2009

\begin{tabular}{|l|c|r|r|}
\hline Tahun & $\begin{array}{c}\text { Luas } \\
\text { Panen } \\
\text { (ha) }\end{array}$ & \multicolumn{1}{c|}{$\begin{array}{c}\text { Produksi } \\
\text { (ton) }\end{array}$} & $\begin{array}{c}\text { Produktivitas } \\
\text { (kw/ha) }\end{array}$ \\
\hline 2001 & 36.610 & 81.720 & 22,32 \\
2002 & 45.718 & 130.251 & 28,49 \\
2003 & 58.716 & 183.998 & 31,34 \\
2004 & 72.529 & 251.214 & 34,64 \\
2005 & 88.378 & 400.046 & 43,80 \\
2006 & 109.792 & 416.222 & 37,91 \\
2007 & 119.027 & 572.784 & 48,12 \\
2008 & 156.436 & 753.598 & 48,17 \\
2009 & 124.798 & 569.110 & 45,60 \\
\hline
\end{tabular}

Sumber: BPS Provinsi Gorontalo

Dari Tabel 1 di atas, dapat dijelaskan dalam kurun waktu 9 tahun, produktivitas jagung di provinsi ini cukup signifikan. Hanya saja pada tahun 2009, produktivitas jagung turun sebesar 2,57 kw/ha.

Pengembangan agropolitan jagung dilaksanakan dengan pendekatan sistem agribisnis. Sistem agribisnis ini terdiri dari beberapa subsistem dan salah satunya yaitu subsistem agriindustri hilir (pengolah produk primer) merupakan subsistem yang bertujuan untuk mengolah produk primer menjadi bahan baku untuk proses produksi di agriindustri lainnya (intermediate product), atau sebagai produk siap konsumsi atau final product (Tatuh, 2004).

Pendekatan sistem agribisnis yang dilakukan pemerintah bisa dilihat dari program pemerintah yaitu program pengembangan Kawasan Industri Agro Terpadu (KIAT) yang telah berdiri sejak Tahun 2007. Program KIAT sejak terbentuknya pada Tahun 2007 sampai dengan saat ini pendanaannya melekat pada DPA SKPD Dinas Kopperindag Provinsi Gorontalo secara keseluruhannya berjumlah Rp1.605.525.000 guna menanggulangi biaya operasional, biaya bahan baku/bahan penolong serta insentif bagi karyawannya. Selain itu, fasilitas tanah, gedung, dan mesin/peralatan telah tersedia.

Program pengembangan KIAT ini diarahkan pada kegiatan yang bersifat sekunder, utamanya dalam merangsang "nilai tambah" sektor primer dalam sebuah aktivitas yang terpadu (KIAT Provinsi Gorontalo). Sektor primer yang dimaksud yaitu sektor pertanian dan perikanan. Dalam hal ini, KIAT termasuk dalam komponen subsistem agriindustri hilir untuk merangsang nilai tambah dari jagung dan komoditi selain jagung yaitu tomat, cabe, jahe, kelapa, dan ikan. Oleh karena itu, sejak awal berdirinya KIAT pada tahun 2007, direncanakan ada 8 unit produksi yang akan diusahakan yaitu unit produksi emping jagung, bakso ikan, pakan ternak, VCO, cabe bubuk, jahe instan, saus tomat, dan biodiesel. Dari kedelapan unit produksi tersebut, yang menjadi prioritas KIAT yaitu unit produksi emping jagung mengingat Gorontalo merupakan daerah agropolitan jagung.

Unit-unit produksi yang beroperasi yaitu hanya unit produksi emping jagung, jahe instan, dan saus tomat. Unit produksi lainnya tidak beroperasi karena masalah pemasaran dan alasan teknis. Dari 3 unit produksi yang beroperasi, yang masih bertahan hingga sekarang yaitu unit produksi emping jagung dan jahe instan. Unit produksi jahe instan pun telah dikembangkan untuk jahe instan dan bajigur. Sementara unit produksi saus tomat sudah tidak beroperasi lagi karena sulitnya pemasaran. Pada perkembangannya, KIAT juga sudah pernah mencoba produksi keripik singkong dan stik jagung. Namun terhenti karena masalah pemasaran. Sulitnya pemasaran mungkin disebabkan kualitas produk yang tidak mampu bersaing dengan produk luar daerah. Pada Desember 2009, KIAT mencoba untuk melakukan inovasi dengan menambahkan unit produksi kacang telur dan kacang disco. Sudah 1 tahun lebih unit produksi tersebut dijalankan, dan ternyata pemasaran dari produk tersebut tidak mengalami kesulitan. Setelah sekian lama melewati proses demi proses serta inovasi, maka unit produksi yang aktif hingga sekarang yaitu emping jagung, kacang telur, kacang disco, jahe instan, dan bajigur. Namun, hanya unit produksi 
emping jagung, kacang telur, dan kacang disco yang aktif berproduksi setiap bulan. Jahe instan dan bajigur hanya berproduksi tiap 2 bulan sekali. Karena bahan baku jahe juga agak sulit didapatkan.

Berdasarkan keberlangsungan proses produksi, maka penelitian ini dikhususkan pada unit produksi emping jagung, kacang disco, dan kacang telur mengingat unit produksi tersebut berproduksi secara terus menerus (setiap bulan). Emping jagung diproduksi dengan berbagai rasa dan ukuran kemasan. Kacang disco dan kacang telur juga dikemas dalam berbagai ukuran kemasan. Untuk memproduksi produk-produk tersebut, dibutuhkan suatu proses yaitu proses pengolahan input/produk primer sehingga tentu saja membutuhkan input dalam hal ini sumberdaya berupa bahan baku, bahan pelengkap, alat-alat/mesin, dan tenaga kerja. Oleh sebab itu diperlukan suatu keahlian/keterampilan dalam mengalokasikan sumberdaya tersebut agar sumberdaya yang ada, bisa dimanfaatkan sebaik mungkin (efisien) sehingga nantinya bisa memberikan keuntungan yang maksimal bagi KIAT. Berapapun sumberdaya yang tersedia, masing-masing unit produksi harus bisa mengalokasikannya dengan baik, agar hasil yang didapatkan juga optimal. Hal inilah yang menjadi ketertarikan peneliti sehingga peneliti mencoba untuk membuat suatu perencanaan produksi dengan menerapkan model linier programming untuk mencari kombinasi produk optimum yang harus diproduksi oleh KIAT agar memberikan keuntungan yang maksimum dengan memperhatikan keterbatasan sumberdaya dan kemudian dibandingkan dengan pola produksi yang telah diterapkan oleh KIAT

\section{METODE PENELITIAN}

\section{Metode Pengambilan Data}

Penelitian ini menggunakan metode studi kasus yang dilaksanakan di Kawasan Industri Agro Terpadu (KIAT) Provinsi Gorontalo pada unit produksi emping jagung, kacang disco, dan kacang telur. Data yang digunakan yaitu data untuk beberapa siklus produksi (dalam 1 bulan) November 2010, khusus untuk data permintaan mengunakan data penjualan bulan Oktober, November, dan Desember 2010.

\section{Konsep Pengukuran Variabel}

Variabel yang diukur dalam penelitian terdiri dari:

1. Variabel keputusan/aktivitas, yaitu: Output $\left(\mathrm{X}_{\mathrm{n}}\right)$, yaitu jumlah produksi emping jagung, kacang disco, dan kacang telur.

a. Untuk emping jagung, outputnya yaitu jumlah produksi emping jagung tiap ukuran kemasan (20 gram, 100 gram, 250 gram, 700 gram/ukuran toples).

b. Untuk kacang disco, outputnya yaitu jumlah produksi kacang disco tiap ukuran kemasan (50 gram, 100 gram, 250 gram, 500 gram, $1,8 \mathrm{~kg} /$ ukuran toples).

c. Untuk kacang telur, outputnya yaitu jumlah produksi kacang telur tiap ukuran kemasan (25 gram, 50 gram, 100 gram, 2 $\mathrm{kg} / \mathrm{ukuran}$ toples)

2. Variabel tujuan, yaitu: Keuntungan (Z), yaitu keuntungan maksimum yang akan dicapai oleh program KIAT dengan memproduksi emping dan kacang, diukur dalam satuan $(\mathrm{Rp})$

3. Variabel kendala, yaitu:

a. Banyaknya bahan baku jagung $(\mathrm{kg})$

b. Banyaknya bahan baku kacang $(\mathrm{kg})$

c. HOK untuk emping dan kacang (hari)

d. Permintaan untuk masing-masing output (kemasan)

Variabel kendala hanya mencakup bahan ba$\mathrm{ku}$, tenaga kerja, dan permintaan. Batasan variabel kendala yaitu sumberdaya yang mampu disediakan oleh KIAT dibatasi dengan dana yang diberikan oleh Disperindag. Sedangkan untuk permintaan, merupakan rata-rata dari hasil penjualan produk untuk 3 bulan terakhir berturut-turut. Bahan pelengkap tidak dimasukkan dalam kendala karena bahan-bahan tersebut dapat segera diadakan jika terjadi kekurangan.

4. Koefisien fungsi tujuan, yaitu:

a. Harga jual terdiri dari harga jual emping jagung, kacang disco, kacang telur tiap ukuran kemasan, diukur dalam satuan (Rp)

b. Biaya produksi yaitu akumulasi biaya yang dikeluarkan untuk penggunaan input faktor produksi emping jagung, kacang 
disco, kacang telur untuk setiap ukuran kemasan, diukur dalam satuan $(\mathrm{Rp})$

\section{Metode Analisis Data}

Penelitian ini menggunakan analisis kuantitatif yaitu dengan menggunakan model linier programming, dimana variabel-variabel yang ada dibuat model matematisnya setelah itu penyelesaiannya dengan menggunakan QM (software untuk riset operasi).

\section{Waktu dan Tempat Penelitian}

Penelitian ini dilaksanakan selama 2 bulan yaitu mulai bulan November-Desember 2010 di Kawasan Industri Agro Terpadu Provinsi Gorontalo pada unit produksi emping jagung, kacang disco, dan kacang telur.

\section{HASIL DAN PEMBAHASAN}

\section{Analisis Primal}

Berdasarkan hasil perhitungan linier programming dengan menggunakan QM maka diperoleh kombinasi produk yang optimal sebagai berikut:

$\mathrm{X} 1$ (emping jagung ukuran kemasan 20 gram): 2545 bungkus

X2 (emping jagung ukuran kemasan 100 gram): 314 bungkus

X3 (emping jagung ukuran kemasan 250 gram): 76 bungkus

X4 (emping jagung ukuran kemasan 700 gram): 130 bungkus

X5 (kacang disco ukuran kemasan 50 gram): 344 bungkus

X6 (kacang disco ukuran kemasan 100 gram): 509 bungkus

X7 (kacang disco ukuran kemasan 250 gram): 331 bungkus

X8 (kacang disco ukuran kemasan 500 gram): 172 bungkus

X9 (kacang disco ukuran kemasan $1.8 \mathrm{~kg}$ ): 7 bungkus

X10 (kacang telur ukuran kemasan 25 gram): 311 bungkus

X11 (kacang telur ukuran kemasan 50 gram): 180 bungkus

X12 (kacang telur ukuran kemasan 100 gram): 854 bungkus
X13 (kacang telur ukuran kemasan $2 \mathrm{~kg}$ ): 7 bungkus

Jumlah produksi optimal dapat dibandingkan dengan produksi aktual KIAT seperti disajikan pada Tabel 2.

Tabel 2. Produksi Optimal dan Produksi Aktual per bulan

\begin{tabular}{|c|r|r|r|}
\hline $\begin{array}{c}\text { Produk } \\
\text { (Aktivi } \\
\text { tas) }\end{array}$ & $\begin{array}{c}\text { Produksi } \\
\text { Optimal } \\
\text { (bungkus) }\end{array}$ & $\begin{array}{c}\text { Produksi } \\
\text { Aktual } \\
\text { (bungkus) }\end{array}$ & $\begin{array}{c}\text { Selisih } \\
\text { (bungkus) }\end{array}$ \\
\hline X1 & 2545 & 7512 & 4967 \\
X2 & 314 & 288 & -26 \\
X3 & 76 & 14 & -62 \\
X4 & 130 & 6 & -124 \\
X5 & 344 & 192 & -152 \\
X6 & 509 & 627 & 118 \\
X7 & 331 & 408 & 77 \\
X8 & 172 & 136 & -36 \\
X9 & 7 & 15 & 8 \\
X10 & 311 & 544 & 233 \\
X11 & 180 & 293 & 113 \\
X12 & 854 & 272 & -582 \\
X13 & 7 & 10 & 3 \\
\hline
\end{tabular}

Sumber: Hasil Analisis LP dan Data

Olahan

KIAT belum bisa dikatakan berproduksi optimal. Karena untuk produk X4 (emping jagung ukuran 700 gram), X5 (kacang disco ukuran 50 gram), dan X12 (kacang telur ukuran 100 gram) terdapat selisih yang cukup besar antara kondisi optimal dan aktual dimana kondisi optimal menunjukkan produksi yang lebih besar. Untuk produk lainnya yaitu X1 (emping jagung ukuran kemasan 20 gram), X6 (kacang disco ukuran kemasan 100 gram), X10 (kacang telur ukuran kemasan 25 gram) dan X11 (kacang telur ukuran kemasan 50 gram) juga terdapat selisih yang cukup besar namun kondisi aktual menunjukkan produksi yang lebih besar. 


\section{Biaya Produksi}

Tabel 3. Biaya Produksi Emping Jagung, Kacang Disco, dan Kacang Telur per Kemasan (bungkus)

\begin{tabular}{|c|r|}
\hline $\begin{array}{c}\text { Produk } \\
\text { (Aktivitas) }\end{array}$ & $\begin{array}{r}\text { Biaya Produksi per } \\
\text { kemasan }\end{array}$ \\
\hline X1 & 472.12 \\
X2 & 2448.17 \\
X3 & 5487.42 \\
X4 & 12530.1 \\
X5 & 1287.98 \\
X6 & 2847.96 \\
X7 & 6637.39 \\
X8 & 12713.78 \\
X9 & 42935.19 \\
X10 & 495.65 \\
X11 & 982.3 \\
X12 & 2355.6 \\
X13 & 37821.98 \\
\hline
\end{tabular}

Sumber: Data Olahan

\section{Penerimaan}

Tabel 4 menyajikan perbedaan antara penerimaan optimal dan penerimaan aktual. Total penerimaan optimal lebih besar daripada total penerimaan aktual, dengan selisih penerimaan sebesar Rp1.054.600 (Tabel 4).
Tabel 4. Penerimaan Optimal dan Penerimaan Aktual

\begin{tabular}{|c|c|c|c|}
\hline $\begin{array}{l}\text { Produk } \\
\text { (Aktivit } \\
\text { as) }\end{array}$ & $\begin{array}{c}\text { Penerimaan } \\
\text { Optimal } \\
\text { (Rp/bulan) }\end{array}$ & $\begin{array}{c}\text { Penerimaan } \\
\text { Aktual } \\
\text { (Rp/bulan) }\end{array}$ & $\begin{array}{c}\text { Selisih } \\
\text { (Rp) }\end{array}$ \\
\hline $\mathrm{X} 1$ & 1.908 .750 & 5.634 .000 & 3.725 .250 \\
\hline $\mathrm{X} 2$ & 1.099 .000 & 1.008 .000 & -91.000 \\
\hline $\mathrm{X} 3$ & 646.000 & 119.000 & -527.000 \\
\hline $\mathrm{X} 4$ & 3.900 .000 & 180.000 & -3.720 .000 \\
\hline $\mathrm{X} 5$ & 602.000 & 336.000 & -266.000 \\
\hline X6 & 2.417 .750 & 2.978 .250 & 560.500 \\
\hline $\mathrm{X} 7$ & 3.475 .500 & 4.284 .000 & 808.500 \\
\hline $\mathrm{X} 8$ & 3.354 .000 & 2.652 .000 & -702.000 \\
\hline X9 & 525.000 & 1.125 .000 & 600.000 \\
\hline X10 & 248.800 & 435.200 & 186.400 \\
\hline X11 & 315.000 & 512.750 & 197.750 \\
\hline $\mathrm{X} 12$ & 2989000 & 952.000 & -2037000 \\
\hline $\mathrm{X} 13$ & 490.000 & 700.000 & 210.000 \\
\hline Total & 21.970 .800 & 20.916 .200 & -1.054 .600 \\
\hline
\end{tabular}

Sumber: Hasil Analisis LP dan Data Olahan

\section{Keuntungan}

Keuntungan diperoleh dari pengurangan biaya produksi terhadap penerimaan. Berikut ini akan disajikan perbandingan keuntungan antara keuntungan optimal (berdasarkan hasil LP) dan keuntungan aktual.

Selisih keuntungan optimal dan aktual yaitu sebesar Rp948.159, dimana keuntungan optimal lebih besar daripada keuntungan aktual (Tabel 5). 
Tabel 5. Keuntungan Optimal dan Keuntungan Aktual

\begin{tabular}{|c|r|r|r|}
\hline $\begin{array}{c}\text { Produk } \\
\text { (Aktivi } \\
\text { tas) }\end{array}$ & $\begin{array}{c}\text { Keuntungan } \\
\text { Optimal } \\
\text { (Rp/bulan) }\end{array}$ & $\begin{array}{c}\text { Keuntungan } \\
\text { Aktual } \\
\text { (Rp/bulan) }\end{array}$ & \multicolumn{1}{c|}{\begin{tabular}{c}
\multicolumn{1}{c}{ Selisih } \\
(Rp)
\end{tabular}} \\
\hline X1 & $707.204,6$ & 2.087 .435 & 1.380 .230 \\
X2 & $330.274,62$ & $302.927,04$ & -27.347 .58 \\
X3 & 228.956 .08 & $42.176,12$ & -186.780 \\
X4 & 2271087 & $104.819,4$ & -2166267.6 \\
X5 & 158934.88 & $88.707,84$ & -70.227 .04 \\
X6 & 968.138 .36 & $1.192 .579,08$ & 224.440 .72 \\
X7 & 1.278 .523 .91 & $1.575 .944,88$ & 297.420 .97 \\
X8 & 1.167 .229 .84 & $922.925,92$ & -244.303 .92 \\
X9 & 224.453 .67 & $480.972,15$ & 256.518 .48 \\
X10 & 94.652 .85 & $165.566,4$ & 70.913 .55 \\
X11 & 138.186 & $224.936,1$ & 86.750 .1 \\
X12 & 977317.6 & $311.276,8$ & -666040.8 \\
X13 & 225.246 .1 & $321.780,2$ & 96.534 .06 \\
Total & 8.770 .206 & $\mathbf{7 . 8 2 2 . 0 4 6}$ & $\mathbf{- 9 4 8 . 1 5 9}$ \\
\hline
\end{tabular}

Sumber: Data Olahan

\section{Analisis Dual}

Berdasarkan hasil perhitungan linier programming dengan menggunakan QM maka diperoleh nilai dual dan slack/surplus dari sumberdaya/input seperti pada Tabel 6 .

Bila dilihat pada Tabel 6, maka dapat dijelaskan bahwa sumberdaya yang bersifat terbatas / habis terpakai yaitu HOK untuk emping dan HOK untuk kacang karena nilai slack $=0$ dan nilai dual $>0$. Sehingga jika HOK untuk emping bertambah 1 hari maka penerimaan akan bertambah sebesar Rp114.732,4. Begitupun dengan HOK untuk kacang, jika HOK untuk kacang bertambah 1 hari maka penerimaan akan bertambah sebesar Rp293.427,3.
Tabel 6. Nilai Dual dan Slack dari Setiap Input

\begin{tabular}{|l|r|r|}
\hline Input/Sumberdaya & \multicolumn{1}{|c|}{ Dual } & \multicolumn{1}{|c|}{ Slack } \\
\hline Jagung & 0 & 64.99548 \\
Kacang tanah & 0 & 57.89008 \\
HOK untuk emping & 114732.4 & 0 \\
HOK untuk kacang & 293427.3 & 0 \\
\hline \multicolumn{2}{|l|}{ Sumber: Hasil Analisis LP }
\end{tabular}

Tabel 7. Nilai Dual dan Slack dari Permintaan

\begin{tabular}{|c|r|r|}
\hline Permintaan & \multicolumn{1}{|l|}{ Dual } & Slack \\
\hline X1 & -173.0222 & 0 \\
X2 & -1115.34 & 0 \\
X3 & -3038.523 & 0 \\
X4 & 0 & 129.9898 \\
X5 & -1845.657 & 0 \\
X6 & -2441.315 & 0 \\
X7 & -7478.287 & 0 \\
X8 & -16456.57 & 0 \\
X9 & -54443.58 & 0 \\
X10 & -75 & 0 \\
X11 & 0 & 0 \\
X12 & 0 & 0 \\
X13 & -2.644816 & \\
\hline
\end{tabular}

\section{Sumber: Hasil Analisis LP}

Produk X4 (Emping jagung ukuran 700 gram) dan X12 (kacang telur ukuran 100 gram) yang tersedia berlebih, ini dapat dilihat pada nilai slack > 0 (Tabel 10). Nilai dual dari kedua produk tersebut bernilai $=0$ sehingga jika masing-masing produk ditambahkan 1 kemasan maka tidak akan mempengaruhi jumlah penerimaan. Untuk produk X11 (kacang telur ukuran kemasan 50 gram) baik 
nilai slack maupun dual, keduanya bernilai 0 . Ini bisa diartikan bahwa produk X11 telah memenuhi permintaan (tidak berlebih) dan juga tidak akan mempengaruhi jumlah penerimaan jika ditambah 1 kemasan X11.

Selain produk-produk yang disebutkan di atas, yaitu X1, X2, X3, X5, X6, X7, X8, X9, X10, dan $\mathrm{X} 13$ semua produk tersebut telah mampu memenuhi permintaan (tidak tersedia berlebih), ini bisa dilihat pada nilai slack $=0$. Nilai dual dari produk-produk tersebut $>0$ dan bernilai negatif sehingga bisa dikatakan bahwa jika terjadi penambahan 1 kemasan produk maka akan mengurangi jumlah penerimaan sebesar nilai dualnya.

\section{Analisis Sensitivitas}

Tabel di bawah ini menunjukkan koefisien fungsi tujuan penerimaan, batas kenaikan dan batas penurunan.

Tabel 8. Koefisien Fungsi Tujuan (Harga), Batas Penurunan, dan Batas Kenaikan

\begin{tabular}{|c|r|r|r|}
\hline $\begin{array}{c}\text { Produk } \\
\text { (Aktivitas) }\end{array}$ & \multicolumn{1}{c|}{$\begin{array}{c}\text { Original } \\
\text { Value }\end{array}$} & \multicolumn{1}{c|}{$\begin{array}{c}\text { Lower } \\
\text { Bound }\end{array}$} & \multicolumn{1}{c|}{$\begin{array}{c}\text { Upper } \\
\text { Bound }\end{array}$} \\
\hline X1 & 750 & -Infinity & 923.02 \\
X2 & 3500 & -Infinity & 4615.34 \\
X3 & 8500 & -Infinity & 11538.52 \\
X4 & 30000 & 24376.45 & Infinity \\
X5 & 1750 & -Infinity & 3595.66 \\
X6 & 4750 & -Infinity & 7191.31 \\
X7 & 10500 & -Infinity & 17978.29 \\
X8 & 19500 & -Infinity & 35956.57 \\
X9 & 75000 & -Infinity & 129443.58 \\
X10 & 800 & -Infinity & 875 \\
X11 & 1750 & -Infinity & 1750 \\
X12 & 3500 & 3500 & Infinity \\
X13 & 70000 & -Infinity & 70002.65 \\
\hline
\end{tabular}

Sumber: Hasil Analisis LP
Dari Tabel 8, maka dapat dijelaskan bahwa jumlah produksi optimum akan tetap optimum jika koefisien masing-masing produk tetap berada pada range batas kenaikan dan batas penurunan seperti pada kolom 3 dan 4 pada Tabel 11 di atas. Untuk X4 dan X12, jumlah produksi akan tetap optimum jika koefisien X4 diturunkan hingga Rp24.376,45 atau dinaikkan sampai besaran harga berapapun (tak terhingga) dan jika koefisien X12 tetap berada pada harga Rp3500 (tidak bisa diturunkan hingga lebih kecil dari Rp3500) atau dinaikkan dinaikkan sampai besaran harga berapapun (tak terhingga). Sehingga bisa dikatakan untuk X4 dan X12 tidak ada batas kenaikkannya untuk tetap mempertahankan jumlah produksi optimum. Sedangkan untuk produk selain $\mathrm{X} 4$ dan $\mathrm{X} 12$ ada batas kenaikkannya namun tidak ada batas penurunannya untuk bisa tetap mempertahankan jumlah produksi optimum (lihat kolom 3 dan 4 Tabel 8).

Tabel 9. Nilai RHS, Batas Penurunan, dan Batas Kenaikan dari Setiap Input

\begin{tabular}{|l|r|r|r|}
\hline \multicolumn{1}{|c|}{$\begin{array}{c}\text { Input/ } \\
\text { Sumberdaya }\end{array}$} & $\begin{array}{c}\text { Original } \\
\text { Value }\end{array}$ & $\begin{array}{c}\text { Lower } \\
\text { Bound }\end{array}$ & $\begin{array}{c}\text { Upper } \\
\text { Bound }\end{array}$ \\
\hline Jagung & 265 & 200 & Infinity \\
$\begin{array}{l}\text { Kacang } \\
\text { tanah }\end{array}$ & 331 & 273.11 & Infinity \\
$\begin{array}{l}\text { HOK } \\
\text { emping }\end{array}$ & 75 & 42.32 & 99.37 \\
$\begin{array}{l}\text { HOK } \\
\text { kacang }\end{array}$ & 75 & 66.76 & 86.58 \\
\hline
\end{tabular}

Sumber: Hasil Analisis LP

Agar jumlah produksi optimal tetap optimal maka sumberdaya jagung dan kacang tanah diijinkan untuk diturunkan kapasitasnya hingga sebesar $200 \mathrm{~kg}$ dan 273,11 kg. Sedangkan untuk HOK emping dan HOK kacang, untuk menjaga jumlah produksi tetap optimal maka secara berurut dapat diturunkan atau dinaikkan pada selang 42,32 $\leq$ HOK emping $\leq 99,37$ dan $66,76 \leq$ HOK kacang $\leq 86,58$ (Tabel 9). 
Tabel 10. Nilai RHS, Batas Penurunan, dan Batas Kenaikan dari Permintaan

\begin{tabular}{|c|r|r|r|}
\hline Permintaan & \multicolumn{1}{|c|}{$\begin{array}{c}\text { Original } \\
\text { Value }\end{array}$} & \multicolumn{1}{c|}{$\begin{array}{c}\text { Lower } \\
\text { Bound }\end{array}$} & \multicolumn{1}{c|}{$\begin{array}{c}\text { Upper } \\
\text { Bound }\end{array}$} \\
\hline X1 & 2545 & 0 & 6607.41 \\
X2 & 314 & 0 & 1126.44 \\
X3 & 76 & 0 & 400.97 \\
X4 & 1 & -Infinity & 130.99 \\
X5 & 344 & 0 & 1016.25 \\
X6 & 509 & 0 & 845.12 \\
X7 & 331 & 0 & 465.45 \\
X8 & 172 & 0 & 239.22 \\
X9 & 7 & 0 & 25.67 \\
X10 & 311 & 0 & 3073.48 \\
X11 & 180 & 0 & 1561.24 \\
X12 & 164 & -Infinity & 854.62 \\
X13 & 7 & 0 & 41.53 \\
\hline
\end{tabular}

Sumber: Hasil Analisis LP

Tabel 10 menunjukkan bahwa untuk produk $\mathrm{X} 4$ dan X12, tidak memiliki batasan penurunan sedangkan batas kenaikan permintaan untuk kedua produk ini secara berurut 130 kemasan dan 854 kemasan untuk tetap menjaga jumlah produksi optimal tetap optimal. Sedangkan untuk produk lainnya selain X4 dan X12 jumlah permintaan harus sama dengan nilai RHS agar jumlah produksi optimal tetap optimal. Jika produk-produk tersebut dinaikkan hingga selang batas kenaikannya, maka jumlah produksi optimal berubah namun jumlah penerimaan optimalnya tetap. Dengan demikian, keuntungannya juga tetap optimal.

\section{KESIMPULAN DAN SARAN}

\section{Kesimpulan}

1. Kombinasi produk yang harus diproduksi (kemasan/bungkus) secara berurut dari X1 sampai X13 yaitu 2545, 314, 76,130, 344, 509, 331, 172, 7, 311, 180, 854, 7. Kombinasi produk tersebut merupakan kombinasi produk yang bisa memberikan keuntungan maksimum.

2. Keuntungan maksimum yang dapat dicapai oleh KIAT dengan memproduksi kombinasi produk pada kesimpulan 1 yaitu sebesar Rp8.770.206

3. Pola produksi KIAT belum optimal, karena untuk beberapa produk masih terdapat selisih yang cukup besar antara produksi optimal dan produksi aktual dimana produksi optimal memberikan hasil yang lebih baik (besar), dan juga belum ada produk aktual yang dihasilkan jumlahnya sama dengan produksi optimal.

\section{Saran}

1. Disarankan agar KIAT dapat membuat suatu perencanaan produksi yang optimum, yaitu perencanaan produksi yang memberikan hasil yang optimum (keuntungan maksimum) dengan memperhatikan keterbatasan sumberdaya/input yang tersedia. Dalam menentukan jumlah produksi, KIAT perlu memperhatikan beberapa hal seperti sumberdaya yang tersedia dan jumlah permintaan.

2. Disarankan agar KIAT mengadakan kerja sama dengan kelompok-kelompok petani sebagai pemasok bahan baku dan juga bekerja sama dengan Dinas Pertanian.

\section{DAFTAR PUSTAKA}

Ahmeth, Adi. 2010. Artikel Tentang Laba. http://adiewongindonesia.blogspot.com/2010/02/arti kel-tentang-laba.html diakses pada 3 November 2010

Anonimous.

http://docs.google.com/viewer?a=v\&q=ca che:dmFv6kgiz2kJ:iirc.ipb.ac.id/jspui/bits $\underline{\text { tream/123456789/1619/4/Murni diakses }}$ pada 18 September 2010

2008 Istilah dalam Keppres. http://berthing.files.wordpress.com/2008/ 09/pengertian-istilah-dalam-keppres.pdf diakses pada 6 Oktober 2010 
2009. Analisis Faktor-faktor yang Mempengaruhi Produktivitas Perusahaan. http://judulskripsi.info/analisis-faktorfaktor-yang-mempengaruhi-produktivitasperusahaan-suatu-kasus-pada-perusahaanjasa-pelaksana-konstruksi-pt-matrixprimatama-bandung diakses pada 18 Sepetember 2010

. Pengertian Industri tenaga kerja, dan produktivitas, serta fungsi produksi.http://digilib.ubaya.ac.id/skripsi/ ekonomi/SP_534_3811226/SP_534_Bab \%20II.pdf diakses pada 5 Oktober 2010 Investasi Provinsi Gorontalo. http://www.indonesia.go.id/id/index.php? op$\underline{\text { tion}=c o m \_c o n t e n t \& t a s k=v i e w \& i d=6129}$ \&Itemid=1854 diakses pada 18 September 2010 .ui.ac.id/onnopurbo/library/libraryref.../Materi_Makalah.doc diakses pada 6 Oktober 2010

2008. Faktor-faktor Produksi. http://kamarche99.wordpress.com/2008/0 9/22/faktor-faktor-produksi/ diakses pada 6 Oktober 2010

Assauri, S. 1999. Manajemen Produksi dan Operasi. Jakarta: Universitas Indonesia. Balai Lektur Mahasiswa, kumpulan kuliah ekonomi industri, seri kuliah no.VI-01, Jakarta 1989, hal 15
Bappeda Gorontalo. Hasil Kajian dan Perencanaan

http://bappeda.gorontaloprov.go.id/index. php?option=com content \&view=section $\underline{\text { \&layout }=\text { blog\&id }=10 \& \text { Itemid }=16 \text { diakses }}$ pada 18 September 2010

Firmansah. 2010. Sektor Pertanian dan Struktur Perekonomian Indonesia. http://metrotvnews.com/index.php/metro main/analisdetail/2010/06/09/23/SektorPertanian-dan-Struktur-PerekonomianIndonesia diakses pada 27 Oktober 2010

Loho, Agnes. 2009. Pemrograman Linier. Manado: Fakultas Pertanian

Mulyadi. 2005. Akuntansi Biaya,edisi ke-6. Yogyakarta: STIE YKPN http://tryusnita.wordpress.com/2009/05/0 6/biaya-berbagai-macam-pengertianbiaya/ diakses pada 16 Oktober 2010

Nasendi, B.O. dan Affendi A. 1985. Program Linier dan Variasinya. Jakarta: PT.Gramedia

Nicholson, W. 1995. Teori Mikro Ekonomi. Jakarta: Binarupa Aksara

Rachmawati, Dinda Karina. 2010. Agribisnis Membangun Pertanian Indonesia. http://blog.ub.ac.id/karinances/2010/05/23 /agribisnis/diakses pada 27 Oktober 2010

Tatuh, 2004. Agribisnis. Manado: Sosek Faperta Yamit, Zulian. 2007. 'Manajemen Kuantitatif Bisnis. Yogyakarta: BPFE 